\title{
Las publicaciones de Jon Sobrino condenadas ¿Es este el pontificado de Benedicto XVI?
}

\section{Prof. Dr. Peter Hünermann*}

En una declaración del 14 de Marzo de 2007 la Congregación para la Doctrina de la Fe ha condenado los dos libros teológicos centrales y muy difundidos del jesuita de San Salvador. Se trata de la obra "Jesucristo liberador: Lectura histórica-teológica de Jesús de Nazaret”, publicado en San Salvador, 1991, y difundido en cinco idiomas; y de un segundo libro, publicado en cuatro idiomas bajo el título "La fe en Jesucristo: Ensayo desde las víctimas", San Salvador, 1999. Entre los teólogos latinoamericanos, Jon Sobrino podría ser el teólogo más reconocido internacionalmente y también el teólogo latinoamericano más apreciado en el ámbito evangélico. Las acusaciones le fueron comunicadas a Jon Sobrino en agosto de 2004, a lo que respondió en marzo de 2005 con un extenso escrito de más de cien páginas.

Antes de la publicación de sus libros, Jon Sobrino los había dado a leer, para su lectura y revisión, a renombrados teólogos latinoamericanos y europeos. En 2004 después de recibir las acusaciones de la Congregación, Sobrino volvió a pedir la opinión de un teólogo europeo. En los informes de todos ellos se constata que la cristología de Sobrino no contiene ningún error.

En 2006 respondió la Congregación para la Doctrina de la Fe y afirmaba lo siguiente: "Se constató que, aunque en algunos puntos el autor ha matizado parcialmente su pensamiento, la Respuesta no resulta satisfactoria, ya que, en

* El autor es profesor emérito de Dogmática en la universidad de Tübingen y Presidente de honor de la Sociedad Europea de Teología Católica.

El texto original fue publicado en Herder Korrespondenz, Heft 4, April 2007. 
sustancia, permanecen los errores que dieron lugar al envío del elenco de proposiciones ya mencionado." La Congregación sigue manteniendo que en varios puntos hay "notables discrepancias con la fe de la Iglesia". Ciertamente no se pretendería juzgar las intenciones subjetivas del autor, pero sí se hace referencia a determinadas proposiciones "que no están en conformidad con la doctrina de la Iglesia”. Se mencionan seis núcleos:

1. Presupuestos metodológicos del autor

2. La divinidad de Jesucristo

3. La encarnación del Hijo de Dios

4. La relación entre Jesucristo y el Reino de Dios

5. La autoconciencia de Jesucristo

6. El valor salvífico de su muerte

A continuación, en una primera parte examinaremos las acusaciones que se relacionan con estos seis núcleos, remitiéndonos también a los textos de Jon Sobrino citados en la Notificación. En un segundo paso, nos fijaremos en el modo de proceder y sus implicaciones para la situación actual de la teología.

\section{Las acusaciones de la Congregación para la Doctrina de la Fe}

\section{Sobre las acusaciones metodológicas}

La primera acusación reza: el "lugar teológico fundamental" de toda teología y también, especialmente, de la cristología es "sólo la fe de la Iglesia", y no lo son los pobres o "la Iglesia de los pobres"; y Jon Sobrino no respetaría, presuntamente, este presupuesto fundamental. Dicha afirmación es simplemente falsa y se basa en una lectura superficial. Ya en el título del capítulo correspondiente (cfr. Jesucristo liberador, San Salvador, 1991, Primera parte, cap. II) Jon Sobrino distingue entre "lugar eclesial" y "lugar social" de la cristología. Y lo explica así: la fuente "primera y más obvia" para una cristología son los "textos en los cuales ha quedado expresada la revelación", el "Nuevo Testamento en especial, que es interpretado normativamente por el magisterio" ( $c f r$. ibid., 51s.). Pero este testimonio normativo y fundamental puede ser considerado e interpretado $-\mathrm{y}$ de hecho siempre lo es- desde perspectivas muy específicas. Se trata, en efecto, de redescubrir el legado de la fe en cada época y para cada época. Se trata, pues, de Cristo, quien está presente. Sobrino dice expresamente que se trata del modo en el cual y por el cual nos acercamos al testimonio. En referencia a dicho modo de acercamiento, Sobrino habla del "lugar" o del "lugar social" (ibid., 51, 65), de ubicarse en América Latina para interpretar adecuadamente el testimonio de Jesucristo. Desde Melchor Cano en la metodología de la teología se habla de "loci alieni", es decir, los "lugares foráneos", que no son los "lugares teológicos propios", los "loci proprii". Sin embargo, estos otros "lugares" foráneos son necesarios para clasificar y desarrollar adecuadamente los temas que se obtienen 
a partir de los lugares teológicos propios. Jon Sobrino expresa la estructura que articula el reconocimiento del Depositum Fidei $y$ la situacionalidad del intérprete del Depositum Fidei con el término "Iglesia de los pobres" (ibid., 62ss.), fórmula que fue utilizada en Medellín y que ya emergió en las discusiones del Concilio Vaticano II. En este modo de proceder, en modo alguno queda eliminado o sustituido el fundamento, el Depositum Fidei. Y por esa razón Jon Sobrino habla expresamente de "eclesialidad general" (ibid., 60) de la cristología y de su "concreción" desde la Iglesia de los pobres (cfr. ibid., 62ss.). Melchor Cano, en su tiempo echaba pestes contra el desprecio y la negación de los "loci alieni" debido a su importancia para la teología, peligro que advertía entre los reformadores. Estos se habrían alejado de la filosofía y de la razón, lo que convertiría a la teología en "santa tosquedad" (sancta rusticitas).

La segunda acusación metodológica consiste en que Jon Sobrino no daría la importancia debida a las afirmaciones del Nuevo Testamento sobre la divinidad de Cristo, su conciencia de Hijo y el sentido salvífico de su muerte, y consideraría a los grandes concilios en su diferencia con el contenido de los textos neotestamentarios. Además, hablaría no sólo del carácter limitado de las fórmulas dogmáticas, sino también de una cierta peligrosidad de dichas fórmulas. Esta segunda acusación no es analizada más en detalle. Se nos remite más bien a los siguientes puntos en los que aparecen, presuntamente, dichos errores metodológicos. Por esa razón, trataremos a continuación cada una de estas cuestiones.

\section{La divinidad de Jesucristo}

La acusación reza así: "Diversas afirmaciones del autor tienden a disminuir el alcance de los pasajes del Nuevo Testamento que afirman que Jesús es Dios ... Según el autor, en el Nuevo Testamento no se afirma claramente la divinidad de Jesús, sino que sólo se establecen los presupuestos para ello: 'En el Nuevo Testamento $[\ldots]$ hay expresiones que, en germen, llevarán a la confesión de fe en la divinidad de Jesús"'. El apartado en que se formula esta acusación concluye con la frase: "La confesión de la divinidad de Jesucristo es un punto absolutamente esencial de la fe de la Iglesia desde sus orígenes y se halla atestiguada desde el Nuevo Testamento".

Esta afirmación indiferenciada contradice el consenso ampliamente predominante entre los exégetas católicos y protestantes. Rudolf Schnackenburg escribe en su comentario a Jn 20,28, al referirse a la confesión de Tomás en el encuentro con el Señor resucitado: "Ante esta confesión de la divinidad de Jesús en labios de Tomás habrá que cuidarse de no caer en el peligro tanto de atenuarla como de fijarla dogmáticamente [...] En la mente del evangelista, la confesión de Tomás aclara que la fe en Jesús, el Hijo de Dios, exigida por la comunidad (cfr. 20, 31) implica el ser-Dios de Jesús. El es el único y verdadero Hijo de Dios, uno con el Padre, no sólo en obras, sino también en esencia (cfr. tomo 2, excur- 
so 9); pero el evangelista no está pensando todavía en la doctrina de las dos naturalezas, sino que liga el ser-Dios de Jesús a la función reveladora y salvífica del Hijo: él es el Mesías, el Hijo de Dios; es decir, él es el Mesías en tanto es el Hijo de Dios, y es el Hijo de Dios en su actuación mesiánica. Esta comprensión funcional también se puede encontrar expresada en la fórmula de la confesión personal "Señor mío y Dios mío"” (ibid., 397). En nota a este texto, Schnackenburg habla de una "afirmación esencialista implícita". Esta diferenciación a la que apunta Schnackenburg es precisamente lo que está en la mira de Jon Sobrino. Tal diferenciación ya había sido advertida por Alois Grillmeier en su gran obra en tres volúmenes sobre el Concilio de Calcedonia, en la que Bernhard Welte dedicó a esta problemática un detallado artículo de carácter sistemático.

Por lo que toca a los pasajes del canon neotestamentario que se citan, surge espontáneamente la pregunta sobre qué obras exegéticas habrán consultado los autores de esta Notificación. Cuando en la Notificación se afirma que Jon Sobrino negaría la continuidad entre el Nuevo Testamento y las afirmaciones conciliares, aunque sí diría que los textos del Nuevo Testamento contienen "en germen" la divinidad de Jesucristo, sólo se puede reaccionar con irritación. ¿Qué significa, entonces, "germen”? Y ¿qué se quiere decir con la imagen de "germen”?

\section{La encarnación del Hijo de Dios}

En base a una breve cita, se achaca a Sobrino que sostendría una "teología del homo assumptus", la cual no sería compatible con la fe católica. No confesaría la unidad de la persona de Jesucristo en dos naturalezas, la divina y la humana.

Tanto en su libro "Jesucristo liberador", como en su segundo libro "La fe en Jesucristo" - $\mathrm{y}$ en éste mucho más detalladamente- Sobrino tiene en cuenta los resultados de la exégesis moderna. El título "Hijo de Dios" tiene una amplia gama de significados; se entiende de distinta manera en los Sinópticos que en las cartas paulinas (Pablo) y en las Deuteropaulinas o en Juan. Jon Sobrino se remite tanto a Oscar Cullmann y Ferdinand Hahn como a Martin Hengel, Anton Vögtle o Joseph Moingt, autores que han tratado la cuestión en torno a los títulos "Hijo de Dios - Hijo del hombre". En base a esas investigaciones, Sobrino va presentando, unos junto a otros, los diversos significados. Se desfigura seriamente su intención y sus afirmaciones si se le achaca que estaría asumiendo simplemente una "teología del homo assumptus". A esta conclusión sólo se puede llegar, si se parte de Calcedonia como la única posibilidad de formular el misterio de Jesucristo, su unión con el Padre. Pero una tal visión ahistórica constriñe la cristología de manera indebida.

En este contexto se critica a Sobrino una proposición en la que da su parecer, de forma breve e inadecuadamente simplificadora, sobre la communicatio idiomatum. Jon Sobrino ya se refirió al tema en su respuesta de 2005, reconociendo que sobre el theologumenon de la communicatio idiomatum no había profundi- 
zado en más detalle, pues no se trataría de un tema que fuera central en su comprensión de la encarnación, y que él estaría dispuesto a corregir esa expresión o a retirarla por completo.

\section{Jesucristo y el reino de Dios}

En sus obras teológicas Jon Sobrino distingue entre Jesús como mediador del reino de Dios y el reino de Dios como mediación. Para él, Cristo es "el mediador definitivo, último y escatológico" del reino de Dios (Jesucristo liberador, 190). Por eso, también se le puede llamar a Cristo, en "las bellas palabras de Orígenes, la autobasileia de Dios, el reino de Dios en persona" (ibid.). Jon Sobrino distingue entre este mediador y la mediación universal del reino de Dios, al que pertenecen tanto Moisés y la tierra prometida, así como "Monseñor Romero y una justicia anhelada" (ibid.).

La acusación reza: "No es suficiente hablar de una conexión íntima o de una relación constitutiva entre Jesús y el Reino o de una 'ultimidad del mediador', si éste nos remite a algo que es distinto de él mismo. Jesucristo y el Reino en cierto sentido se identifican".

Esta acusación es, ciertamente, difícil de comprender, pues Sobrino busca aclarar y determinar con precisión el "en cierto sentido". Sobrino tampoco niega en modo alguno "la singularidad y unicidad" de la mediación de Cristo, ni la "universalidad" y la "insuperabilidad" de esta mediación. Esto no significa, sin embargo, que no se deba hablar de una mediación universal en el sentido en que la interpreta Sobrino. En este sentido, en definitiva sólo a la Iglesia se le ha confiado la misión de Jesucristo. Ella la lleva a plenitud en el Espíritu. Y ella es la que media en esa misión. Por lo demás, hay que afirmar que el Espíritu sopla donde quiere, y que está actuando en la historia de los hombres en vistas al reino de Dios.

En este contexto se acusa también a Jon Sobrino: "la condición de mediador de Jesús le viene sólo de su humanidad: 'La posibilidad de ser mediador no le viene, pues, a Cristo de una realidad añadida a lo humano sino que le viene del ejercicio de lo humano' (La fe en Jesucristo, 253)". El sentido de esta afirmación es claramente precisado por el autor: no se trata de la natura humana, sino de "lo humano" (ibid., 257), de la realidad humana que el Hijo del hombre lleva a plenitud de tal modo que brilla allí lo más profundo y acabadamente humano, lo escatológicamente humano, y de tal manera que es, a su vez, salvífico. Según esto, no se trata, de acuerdo a Sobrino, de ningún poder especial, que se añadiría al ser humano de Jesucristo. Se pasa por alto que Jon Sobrino hace suyo un topos patrístico muy importante, como se encuentra en la antropología teológica de Máximo Confesor ("Más allá del hombre, él [Jesucristo] opera lo humano... mostrando, que la energeia humana se ha fusionado con la dynamis divina"). Pero a Sobrino se le hace decir que de esa forma descuida el que Cristo sea el "Hijo bien amado" de Dios. 


\section{La autoconciencia de Jesucristo}

Remitiéndose a Hans Urs von Balthasar, Karl Rahner, Helmut Riedlinger y otros teólogos, Jon Sobrino caracteriza a Jesucristo como quien camina con $f e$ en Dios, por cierto con una fe profunda y perfecta (cfr. Jesucristo liberador, 266270). En ello, Sobrino no sólo se remite a teólogos sistemáticos, sino también a exegetas que han interpretado los diversos textos correspondientes del Nuevo Testamento. Contra esta posición se objeta: "La unión hipostática y su misión de revelación y redención requieren la visión del Padre (se piensa evidentemente en la visio beatifica, nota del autor) y el conocimiento de su plan de salvación". Al respecto la Notificación se remite a Jn 6,$46 ; 1,18$, pero también a textos como Mt 11, 25-27; Lc 10, 21-22. A los autores de la Notificación les pasa inadvertido que Pío XII en "Mystici corporis" habla todavía, ciertamente, de visio beatifica de Jesucristo durante su vida terrena; pero Juan Pablo II evita el término "visio beatifica", como también el Catecismo Universal. Juan Pablo II habla de un "conocimiento y experiencia peculiares de Dios", y el Catecismo de un "conocimiento interno e inmediato" del Padre.

\section{El valor salvífico de la muerte de Jesús}

La pregunta de cómo Jesús fue al encuentro de su muerte y cómo la comprendió fue arduamente discutida a raíz de la afirmación de Bultmann: "Difícilmente esa ejecución (la de Jesús, nota del autor) puede ser comprendida como consecuencia lógicamente necesaria de su actividad; sucedió, más bien, por una mala interpretación de su actividad como actividad política. Históricamente, habría sido, pues, un destino absurdo. No podemos saber si y de qué forma Jesús encontró sentido a su muerte. No se puede excluir la posibilidad de que se haya derrumbado".

Este tipo de argumentos, publicados en 1960, dieron pie en aquel tiempo a un buen número de trabajos exegéticos, que Jon Sobrino retoma en su exposición. Su síntesis recuerda mucho las tesis presentadas entonces por Heinz Schürmann. Schürmann distingue cuidadosamente - como la gran mayoría de exegetas- entre las interpretaciones de la muerte de Jesús que fueron formuladas después del acontecimiento pascual, y las palabras que, con gran probabilidad, pueden ser atribuidas al mismo Jesús durante su vida. Al explicar las afirmaciones que el Nuevo Testamento atribuye a Jesús, existen entre los exegetas posiciones que, en último término y comprensiblemente, difieren unas de otras; así, Rudolf Pesch cuenta entre las palabras históricas de Jesús las palabras sobre el cáliz de Mc 14, 24 e inscribe la idea de expiación en el contexto prepascual. De forma general Sobrino se remite a las interpretaciones neotestamentarias de Leonardo Boff, Edward Schillebeeckx, Xavier Léon-Dufour, José Ignacio González Faus, aunque en este punto es más cauto (crf. Jesucristo liberador, 321). Insiste, sin embargo, en que la interpretación pospascual de la muerte "tiene un importante núcleo 
histórico que apunta a lo que Jesús pensó sobre su propia muerte. Lo decisivo consiste en que Jesús afirma que su vida es 'para', 'en favor de' (yper) los demás y que eso produce un fruto positivo en los demás. Es la comprensión de la vida de Jesús como servicio y, al final, como servicio sacrificial" (ibid., 322). De esta forma, Jon Sobrino traduce al español una fórmula que Wilhelm Thüsing ha utilizado repetidamente: Jesucristo realiza su vida y su muerte como "pro-existencia". Fidelidad a Dios hasta el final, hasta el extremo, servicio a los hombres hasta el final, hasta el extremo: ésta es la manera cómo Jesús vivió, cómo fue al encuentro de su muerte y cómo murió. Y con ello en la vida y en la muerte de Jesucristo se pone de manifiesto "lo humano verdadero", el sentido verdadero, más profundo, abismal, de la humanidad. Y esta humanidad consumada es el lugar de la presencia de Dios. El amor de Dios en la cruz es real, y allí se hace presente en toda su insondabilidad. "Jesús es iniciativa de Dios, y también lo es, escandalosamente, la cruz: 'Dios entregó a su propio Hijo por nosotros' (Rm 3, 28)" (ibid., 374). "La palabra final del NT sobre la cruz de Jesús es que en ella se ha expresado el amor de Dios" (ibid., 375).

La acusación contra la teología de la cruz de Sobrino reza: "La redención parece reducirse a la aparición del homo verus, manifestado en la fidelidad hasta la muerte. La muerte de Cristo es exemplum y no sacramentum (don). La redención se reduce al moralismo". Para aclararlo se añade: "no se trata de una causalidad eficiente, sino de una causalidad ejemplar". El texto en el que Jon Sobrino alude al par de conceptos "causalidad eficiente" - "causalidad ejemplar", dice textualmente: "Esta eficacia salvífica se muestra más bien a la manera de la causa ejemplar que de la causa eficiente. Pero no quita esto que no sea eficaz: ahí está Jesús, el fiel y misericordioso hasta el final, invitando y animando a los seres humanos a reproducir ellos el homo verus, lo humano verdadero" (ibid., 374). Esta única alusión al par de conceptos de la tradición aristotélica y escolástica manifiesta claramente, por una parte, que Sobrino no está tratando sobre la doctrina de la causalidad ni de conceptualizarla con precisión. La utiliza en un sentido más amplio, más bien como ocasión para hacer una aclaración con lo que se remonta a un topos patrístico. En la cristología agustiniana, Jesucristo es esencialmente comprendido como "ejemplar" ("Exemplar") (Wilhelm Geerlings), de modo que la fuerza y dinámica más profunda es el Espíritu de Jesucristo, que es el Espíritu del Padre. Y así como en Sobrino Jesús mismo y su cruz son caracterizados como "iniciativa de Dios", así su cruz es caracterizada como expresión del amor de Dios a los hombres (cfr. ibid., 375). En este contexto, Jon Sobrino remite a numerosos textos de la Escritura, como por ejemplo $1 \mathrm{Jn} 4,10 ; \mathrm{Rm} 5$, 6-8 etc. Si esto es así, no es fácil de entender que Sobrino esté en oposición al Decreto de Trento sobre la justificación o a la Constitución sobre la Iglesia del Vaticano II (LG, n.7). 


\section{El caso Jon Sobrino y la situación actual de la teología}

Este resumen de las acusaciones a la teología de Jon Sobrino, así como una visión panorámica a sus afirmaciones y a su manera de argumentar, habrá dejado en claro al lector con formación teológica que, junto a Jon Sobrino, en el banquillo de los acusados están los exegetas y teólogos sistemáticos más respetados, tanto católicos como protestantes. Aunque no lo hemos podido desarrollar suficientemente, es sabido que en sus publicaciones Jon Sobrino lleva a cabo un serio diálogo con sus colegas de la teología sistemática, evangélicos y católicos.

La Notificación contrapone a su ensayo una cristología según la cual las afirmaciones de la teología de los concilios debieran estar en relación de identidad con los textos del Nuevo Testamento. Las argumentaciones se mueven totalmente en un esquema conceptual "metafísico", que también utilizan los concilios. Los conceptos más importantes son: la naturaleza divina y la naturaleza humana de Jesucristo, la unión hipostática, la doctrina de la anhipostasía de la naturaleza humana de Jesucristo, la doctrina de la causalidad de Aristóteles en su versión escolástica. Se trata de un condensado de cristología neo-escolástica como criterio para la teología actual. Desde ahí se comprende la irritación que la Notificación ha provocado entre los teólogos. Es imposible integrar en este esquema ni los resultados exegéticos ya adquiridos, ni las afirmaciones sistemáticas actuales. Una pregunta delicada se impone: ¿Es este tipo de teología —un verdadero ojo de aguja- el "portal" por el que en el futuro tendrá que pasar el trabajo y la investigación de la teología? En definitiva, esta Notificación representa el primer acto importante y público del nuevo Prefecto de la Congregación para la Doctrina de la Fe y de su equipo de colaboradores. ¿Es la Notificación también el nuevo modelo de la política de Benedicto XVI por lo que toca a la teología? Ambas cosas serían fatales. Llaman a corregir el rumbo.

Hace ya más de 50 años Bernhard Welte hizo un minucioso análisis de los presupuestos filosóficos de la cristología conciliar, sobre todo la de Calcedonia, y con ello mostró tanto los límites de Calcedonia como las preguntas que piden respuesta, y a las que la cristología se ve enfrentada todavía hoy. A mediados de los años setenta precisó de nuevo el análisis y las tareas que se plantean ( $c f r$. B. Welte, Gesammelte Schriften IV/2). Dicho resumidamente a modo de tesis, y, por lo tanto, brevemente: "La Biblia expresa... el mensaje y la revelación de Jesús predominantemente como el acontecimiento (Ereignis) de la cercanía del reino de Dios, que se manifestó en una secuencia específica de otros acontecimientos concretos. De ahí que en la Biblia se describa menos qué es, y se narre y se anuncie más bien qué aconteció... En el acontecimiento acontece algo, y acontece de tal manera que, surgiendo desde sí mismo y abriéndose, atañe y llama al creyente o al oyente dispuesto a la fe. En el caso de que éste se abra, penetra en lo más suyo propio o lo llama a lo más suyo en verdad" (ibid., 125). Por el contrario, "la metafísica se ha enseñoreado de Nicea, de la Iglesia y del pensamiento 
teológico. Esto significa, entonces, que el acontecimiento originario de la revelación, en su condición de acontecimiento, ha pasado a un segundo plano. Así, la pregunta fundamental ya no es: ¿qué sucedió y qué sucede aún?... Como fundamental, surge más bien una pregunta de carácter totalmente distinto: ¿qué es? Esta pregunta tiene, claramente, un sentido estático; va en otra dirección, aunque no excluye lo anterior, lo que ha sucedido y lo que sucede. Lo que plantea es: ¿qué es en Jesús lo que aparece como permanente? Y ¿cómo se puede constatar? Así, el acontecimiento salvífico, su narración y su anuncio, se convierte en 'objeto' en cuanto 'ousia' para una nueva forma del pensar. Lo 'acontecimental' del pensamiento cristiano y cristológico más antiguo poco a poco quedan proyectados en un nuevo plano, es decir, en el plano metafísico, y de esta manera el acontecimiento aparece como 'essentia' —'ousia' - y no ya como acontecimiento" (ibíd., 127).

Welte describe como finalidad del trabajo teológico llegar a captar "a través del lenguaje metafísico el lenguaje bíblico". "Se originaría así una posibilidad de interpretación, flexible, que, a través de la dogmática y de los grandes Concilios, puede percibir la Biblia de manera viva y sin violentarla, y que puede, a la vez, comprender los grandes concilios y sus declaraciones como exégesis normativa del mensaje bíblico para una gran época de nuestra historia, inmensamente fecunda, y también inmensamente cuestionable, la cual, en cualquier caso, ha llegado a su fin" (ibíd., 130). No es ninguna casualidad que tanto en Welte como en Sobrino surjan las mismas categorías centrales: en lugar de "naturaleza humana", por ejemplo, "el aparecer de lo verdadero humano" en Sobrino, o "el acaecer del hombre integral" (ibíd., 130) en Welte.

Por todas partes se está trabajando a partir de este desafío teológico. A favor de esa tarea está Jon Sobrino en América Latina, y muchos otros teólogos en Norteamérica y Sudamérica, en Europa, Asia y África. Y el proceso está en curso no solo en la cristología. Afecta igualmente al problema difícil, y todavía más fundamental, de la doctrina trinitaria. Hay que alegrarse de numerosos trabajos filosóficos, que también redundan en provecho de la teología sistemática en este arduo trabajo del concepto

¿Qué se desprende de todo lo dicho? Dos conclusiones se imponen:

1. No se puede pasar por alto que para el caminar de la Iglesia en el futuro es de importancia irrenunciable la relación entre el Papa y los obispos, por una parte, y los teólogos, por otra. La Congregación para la Doctrina de la Fe hoy percibe la importantísima función del control de calidad de la teología. Para ello debe preocuparse de que la teología desarrolle verdaderamente la ratio fidei. Si desde la segunda mitad del siglo XIX se ha llegado, una y otra vez, a conflictos que dañan el crédito de la Iglesia y su caminar en la fe, el problema no reside simplemente en las personas que allí trabajan, ni en su formación, amplia o menos profunda. Tales 
deficiencias fluyen como potencial de conflictos. La razón radica, fundamentalmente, en que la Congregación para la Doctrina de la $\mathrm{Fe}$ - organización que sucedió al Santo Oficio- en el fondo tiene todavía hoy la estructura de una oficina de censura de la primera modernidad (siglos XVII-XVIII), tal como existió en todos los estados europeos. El moderno control de calidad en el ámbito de las ciencias se estructura de manera diferente, opera fundamentalmente en conjunción con los científicos. Y en los procesos de decisión de tipo político-científico y administrativo-científico incluye - según las posibilidades- a autoridades científicas. La ratio fidei se ha de elaborar hoy en una sociedad educativa de gran complejidad, con graves problemas y rechazos sociales, económicos y humanos. Apunta a un grado de complejidad de la que, en su aspecto técnico, una oficina de censura del tipo antiguo no ha estado a la altura. La Congregación para la Doctrina de la Fe necesita una reconfiguración inteligente.

2. Por lo que toca a la condena de los escritos de Jon Sobrino, el caso que ahora nos ocupa, más que recomendable, sería necesario que a la presente Notificación siguiese una segunda Notificación —como sucedió con las Instrucciones sobre la Teología de la Liberación- que muestre otra orientación en su modo de proceder. 